\title{
Laboratorium Kit Sederhana Untuk Pengolahan Citra Digital dan Instrumentasi Cerdas
}

\author{
Dede Irawan Saputra*), Susanto Sambasri, Jena Maulana, Cecep Andi Mulyadi \& Lucky Aunillah \\ Jurusan Teknik Elektro Fakultas Teknik Universitas Jenderal Achmad Yani \\ dedeirawan.saputra@lecture.unjani.ac.id
}

\begin{abstract}
Abstrak
Proses utama dalam pembelajaran adalah adanya keterlibatan seluruh potensi mahasiswa baik dari segi kognitif, afektif dan psikomotor. proses pembelajaran pada praktikum merupakan salah satu proses yang cocok untuk mengamati mahasiswa dari segi kompetensi. Ketrbatasan alat peraga praktikum/trainer/laboratorium kit terkadang menjadi permasalahan pada sebuah praktikum yang memerlukan pemahaman konsep yang luas seperti pada mata kuliah citra digital dan instrumentasi cerdas. Tujuan dari penelitian yang dilaksanakan adalah untuk mendemonstrasikan konsep pembuatan laboratorium kit sederhana untuk praktikum. Kit tersebut diperuntukan bagi dosen atau asisten praktikum pada mata kuliah pengolahan citra digital dan insrumentasi cerdas. Laboratorium kit tersebut terdiri dari skenario tiga persimpangan jalan raya terskala yaitu 1:100. Adapun luas dari laboratorum kit adalah $90 \mathrm{~cm} \mathrm{x}$ $48 \mathrm{~cm}$. Kit tersebut dipasangkan tiga buah kamera sebagai sensor untuk mengambil gambar dari tiap simpang, serta kendaraan mini yang digunakan sebagai objek yang akan dideteksi dapat diletakan disetiap lajur. Laboratorium kit dilengkapi pula satu buah mikrokontroler dan komputer sebagai media pemrograman dan kontroler beserta LCD. Dalam rangka memeriksa dampak dari penggunaan laboratorium kit tersebut, sebuah model pembelajaran PBL dapat digunakan pada proses praktikum. Berdasarkan hasil aplikasi laboratorium kit untuk pengolahan citra digital dan instrumentasi cerdas, menunjukan bahwa kit tersebut dapat memberikan ilustrasi tentang proses pengolahan citra dan instrumentasi cerdas serta dapat memahami aplikasi secara rill. Kedepannya pengembangan hasil dari penelitian dapat berpotensi untuk diaplikasikan pada kegiatan praktikum tingkat sarjana.

Kata Kunci: laboratorium kit, pengolahan citra digital, instrumentasi cerdas, problem based learning
\end{abstract}

\section{Pendahuluan}

Pada program studi teknik elektro dengan kelompok keahlian teknik kendali dan instrumentasi terdapat mata kuliah diantaranya memerlukan praktikum, diantara mata kuliah tersebut terdapat mata kuliah Pengolahan Citra Digital dan mata kuliah Instrumentasi Cerdas. Adapun capaian pembelajaran pada mata kuliah tersebut mahasiswa mampu memahami tentang piranti dan algoritma yang digunakan dalam menunjang sistem. Mata kuliah tersebut mencakup kuliah tatap muka dan praktikum agar pemahaman konseptual dapat diintegrasikan dengan kondisi rill. Setiap kegiatan praktikum biasanya ditunjang dengan media pembelajaran yang digunakan sebagai sarana aplikasi teori yang sudah dipelajari. Di berbagai negara berkembang, mata kuliah biasanya di dukung dengan media pembelajaran caggih untuk mengarahkan kegiatan praktikum pada kondisi yang ideal [1]. Akan tetapi di beberapa tempat memiliki keterbatasan perlengkapan penunjang mata kuliah sehingga membuat mahasiswa mengalami kesulitan dalam untuk menuangkan pengalaman secara konsep dalam proses pembelajaran [2].

Proses pembelajaran pada praktikum merupakan salah satu proses yang cocok untuk mengamati kompetensi mahasiswa. Pada praktikum biasanya digunakan metode pembelajaran aktif serta model pembelajaran yang menuntut mahasiswa dapat menyelesaikan suatu permasalahan atau pun proyek. Kegiatan tersebut merupakan hal yang sangat penting dalam pembelajaran teknik. Keluaran dari kegiatan praktikum diharapkan mahasiswa dapat mempermudah untuk melaksanakan pekerjaan dimasa yang akan datang serta mempunyai pengalaman secara teknis dan teori [3].

Permasalahan yang dihadapi pada proses pembelajaran salah satunya adalah keterbatasan sumber pembelajaran dan perlengkapan praktikum sehingga mahasiswa tidak bertambah pengalaman praktiknya dalam pembelajaran dan proses pembelajaran tidak optimal karena peralatan praktikum tidak memadai. Salah satu solusi alternatif untuk menyelesaikan permasalahan tersebut dapat menggunakan komputer dan simulasi. Akan tetapi di butuhkan perangkat lunak seperti Matlab, Scilab, Labview dll.

Peragka lunak tersebut ada yang bersifat versi ujicoba dan ada yang berlisensi. Di beberapa tempat, untuk membeli lisensi untuk aktivasi perangkat lunak tersebut terkadang tidak dapat dijangkau oleh keuangan lab. Begitu pun sulitnya realisasi plan yang menggunakan sistem fisik karena harganya yang sangat mahal. Berdasarkan 
hal tersebut, diperlukan sebuah pengembangan perlengkapan praktikum sesuai dengan kepentingan masing-masing.

Beberapa penelitian telah dilakukan untuk menyelesaikan masalah tersebut dengan berbagai strategi seperti pemanfaatan pemodelan dan simulasi hardware in the loop [4], perancangan modul embeded berbasis mikrokontroler [5], dan simulator SCADA [6]. Sedangkan terkait pengolahan citra dapat dijumpai pada [7] yang menggunakan simulator, serta simulasi lampu lalu lintas otomatis berbasis logika fuzzy [8] dan untuk subjek instrumentasi cerdas dapat dijumpai seperti pengembangan trainer kit logika fuzzy berbasis mikrokontroler [9], simulasi logika fuzzy berbasis mikrokontroler dengan antar muka menggunakan Labview [10], dan simulasi logika fuzzy berbasis mikrokontroler dan Matlab [11]. Bagaimana pun masih ditemukan permasalahan yang bertahan seperti kit lab tidak dapat secara detail mendeskripsikan dan mengilustrasikan kondisi rill di lapangan.

Adapun tujuan dari penelitian adalah untuk mendemontrasikan sebuah perancangan baru dari kit praktikum yang sederhana dan terjangkau dengan tujuan agar mendukung proses pembelajaran dan praktikum pada mata kuliah pengolahan citra digital dan mata kuliah instrumentasi cerdas. Perbedaan dengan kit praktikum lain adalah dapat dikategorikan sebagai kit yang mudah di buat. Kit tersebut terdiri dari mikrokontroler, LCD display, GUI simulator dan simulator. Dimensi dari kit tersebut disusun sedemikian rupa agar menjadi kit yang relatif kompek dan portabel sehingga dapat digunakan pada tempat yang berbeda.

Pada kit tersebut mencakup sistem kendali antrian tiga persimpangan jalan dengan skenario menghitung jumlah kendaraan menggunakan algoritma pengolahan citra Bacground Substrtaction dan skenario pengambilan keputusan menggunakan algoritma logika fuzzy dengan dua buah masukan dan satu keluaran dengan metode Mamdani. Kedua skenario tersebut merupakan dasar dari beberapa algoritma yang sering digunakan di industri.

\section{Diskusi}

\subsection{Pengolahan Citra Digital}

pengolahan citra adalah suatu metode yang digunakan untuk mengolah gambar sehingga menghasilkan gambar yang sesuai dengan yang diinginkan. Pengambilan gambar dalam pengolahan citra dapat dilakukan dengan memasukan gambar dari berkas yang sudah disiapkan ataupun masukan citra dapat berupa hasil sensor kamera.

adapun tahap pengolahan citra digital adalah:

1. Akuisisi citra, merupakan tahap awal untuk mendapatkan citra digital. Tujuan akuisisi citra adalah untuk menentukan data yang diperlukan dan memilih metode perekaman citra digital.

2. Pre-processing, menjamin kelancaran proses berikutnya misalnya dengan menentukan bagian citra yang akan di observasi.

3. Segmentasi adalah salah satu metode penting untuk mengubah citra input kedalam citra output berdasarkan atribut yang diambil.

4. Representasi dan deskripsi, bagian ini untuk mempresentasikan suatu wilayah sebagai suatu daftar titik-titik koordinat. Selanjutnya melakukan deskripsi dengan cara seleksi ciri yakni untuk memilih informasi kuantitatif dari ciri yang ada untuk membedakan kelas-kelas objek secara baik dan ekstrasi ciri yakni untuk mengukur besaran kuantitatif ciri setiap pixel.

5. Pengenalan dan interpretasi, tahap ini bertujuan untuk memberi label pada objek yang informasinya disediakan oleh descriptor, kemudian interpretasi untuk memberi arti pada objek-objek yang dikenali.

6. Basis Pengetahuan, Sebagai basis data pengetahuan berguna untuk memandu operasi dari masing-masing modul proses dan mengontrol interaksi antar modul-modul tersebut.

\subsection{Instrumentasi Cerdas}

Algoritma kecerdasan yang digunakan adalah logika fuzzy. Kendali logika fuzzy disebut juga Fuzzy Inference System/FIS adalah sistem kendali yang menggunakan konsep teori himpunan fuzzy, aturan fuzzy if-then, dan fuzzy consequent.

Dalam rangka membentuk sistem fuzzy, terdapat tiga tahapan yang harus dilakukan yaitu seperti pada Gambar 1 menunjukkan tiga tahap tersebut lengkap dengan parameter-parameter yang diperlukan. Kecerdasan yang dibangung menggunakan logika fuzzy merupakan sebuah teknik reasoning atau penalaran yang digunakan untuk menyelesaikan suatu permasalahan dengan merepresentasikan masalah tersebut menjadi sebuah pengetahuan menggunakan bahasa yang lazim digunakan manusia sehari-hari.

Masalah yang biasa diselesaikan oleh algoritma logika fuzzy adalah masalah ketidakpastian sehingga algoritma tersebut sangat cocok digunakan untuk diimplementasikan sehari-hari. 

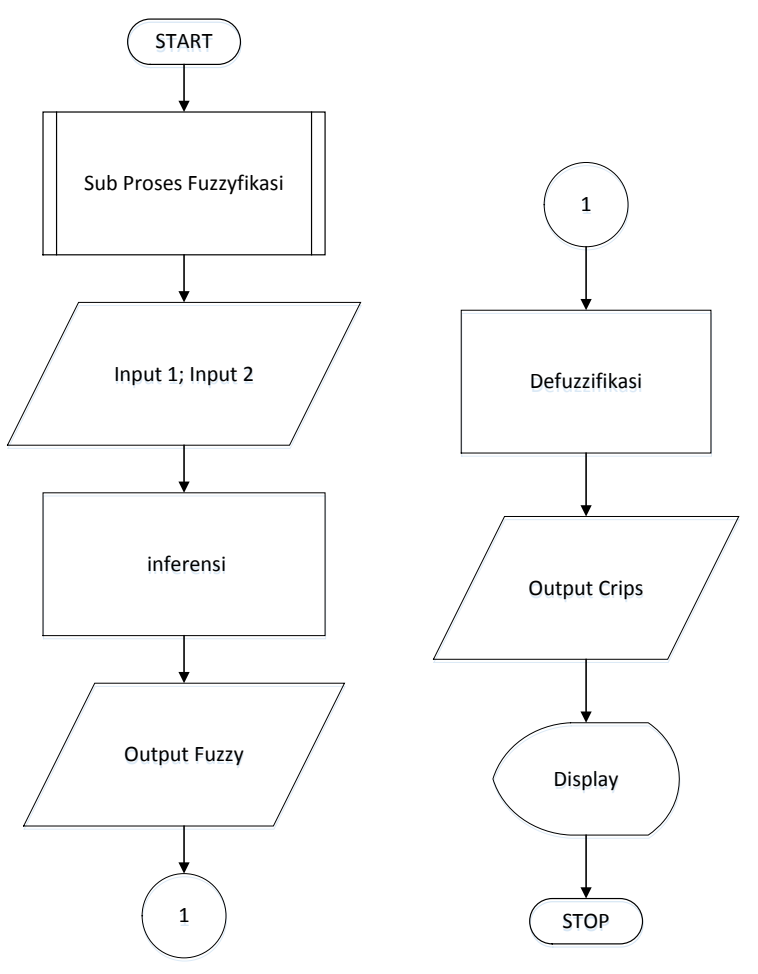

Gambar 1 Tahapan sistem fuzzy logic control

Fuzzifikasi adalah Memproses crisp input menjadi Fuzzy input yang berupa membership function, crisp input jumlah kendaraan 5 akan ditransformasikan sebagai "Padat". Didalam Fuzzifikasi terdapat proses Subset membership function antara lain triangle trapezium dan gaussian.

Rule evaluation adalah penggunaan Rule untuk menentukan aksi Control apa yang harus dilakukan dalam merespon masukan. Berikut adalah format rule yang biasa digunakan dalam Fuzzy : If Antecedent 1 AND Antecedent 2 AND ...Then Consequent 1 AND Consequent 2. Untuk menentukan jumlah Rule Base yang digunakan, dapat digunakan persamaan sebagai berikut:

$$
\text { nRules }=Z x V
$$

Defuzzifikasi adalah mengubah hasil dari inferensi merupakan himpunan logika fuzzy atau fungsi keanggotaan logika fuzzy dengan keluaran yang dihasilkan merupakan suatu bilangan pada domain himpunan fuzzy tersebut menjadi output tegas agar dapat digunakan untuk mengendalikan suatu proses.

\subsection{Perancangan Perangkat Keras}

Mikrokontroler yang digunakan pada kit simulator adalah jenis ATmega16. Rangkaian sistem minimum ATmega16 untuk laboratorium kit menggunakan oscillator $16 \mathrm{MHz}$ seperti pada Gambar 2 yang disimulasiakn sebelumnya menggunakan perangkat lunak proteus.

\subsection{Perancangan Sistem pada laboratorium kit}

Pada sistem laboratorium kit menggunakan skenario traffic light adaptive karena sangat menunjang proses pengolahan citra dan pengolahan algoritma kecerdasarn buatan. Gambar 3 menunjukkan beberapa blok sistem untuk mendukung proses kerja sistem laboratorium kit. Adapun tahapan-tahapan blok diagram pada Gambar 3 dijelaskan sebagai berikut. Proses dari pengolahan dan analisa citra pertama-tama yaitu dengan pengambilan referensi citra dan citra objek dari kamera kemudian setelah pengambilan data, citra dimuat untuk diolah menjadi masukan, dengan dikonversi tiap-tiap citra ke ruang warna grayscale, untuk memudahkan proses background subtraction. Tahapan proses pengolahan citra background subtraction tersebut dapat dilihat seperti pada Tabel 1.

Tabel 1 Tahapan background subtraction

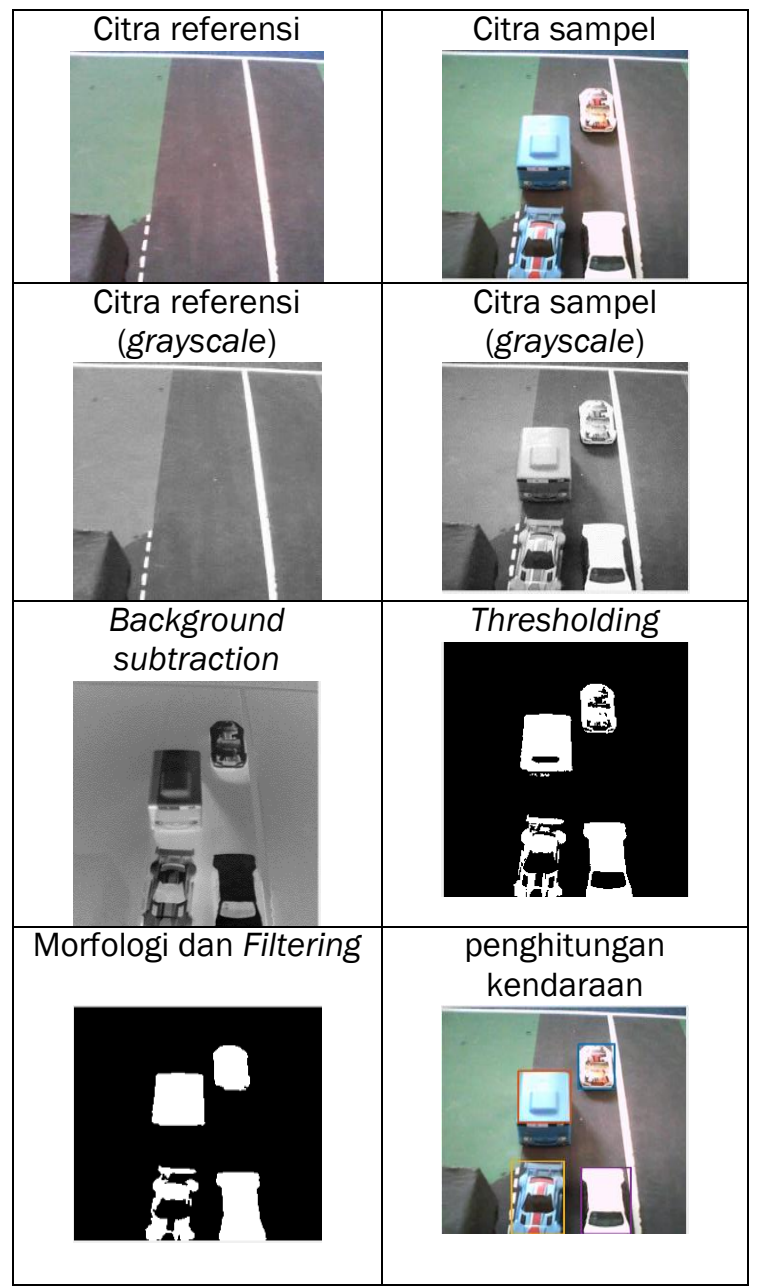




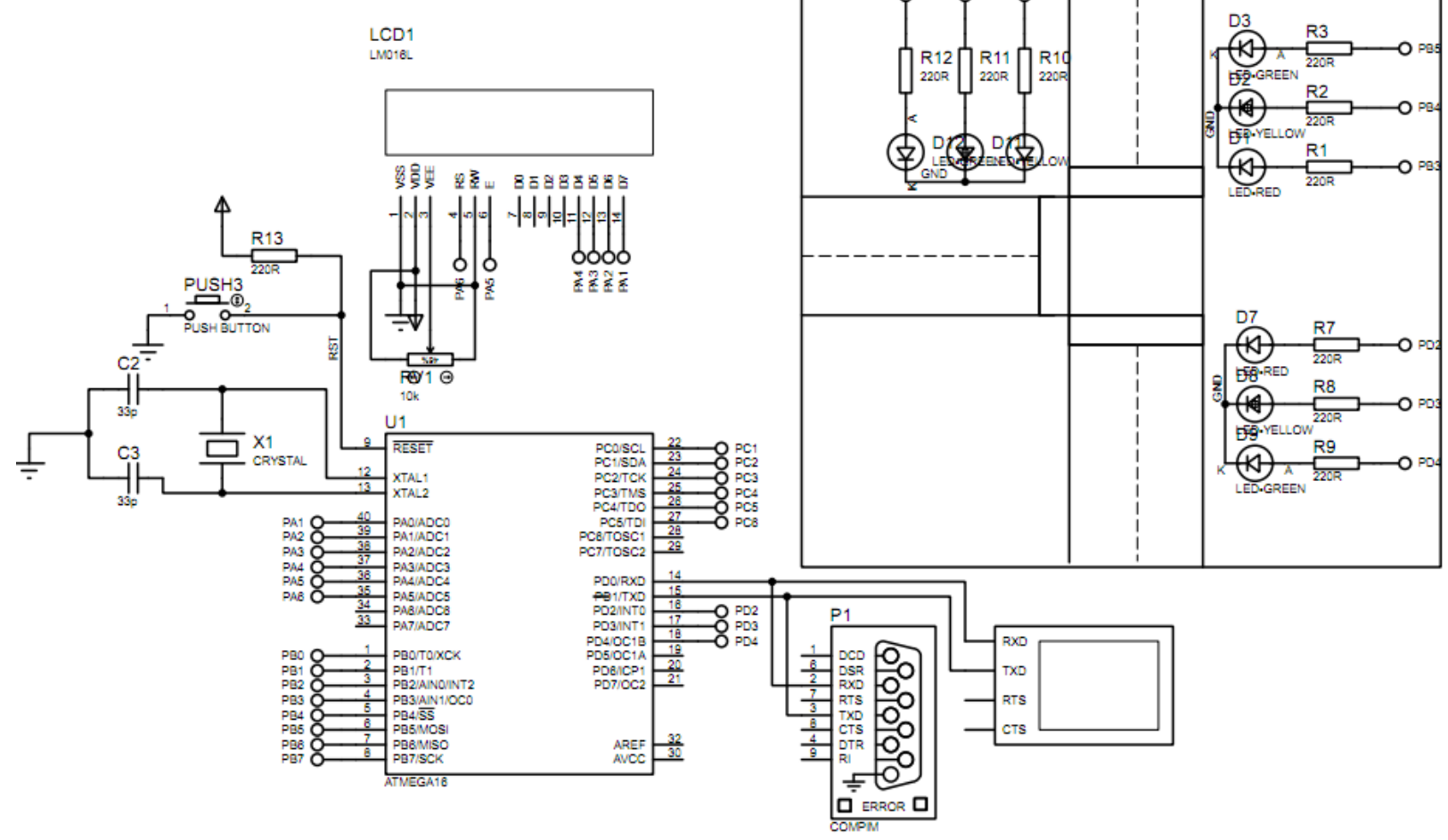

Gambar 2. Skematik perangkat keras laboratorium kit
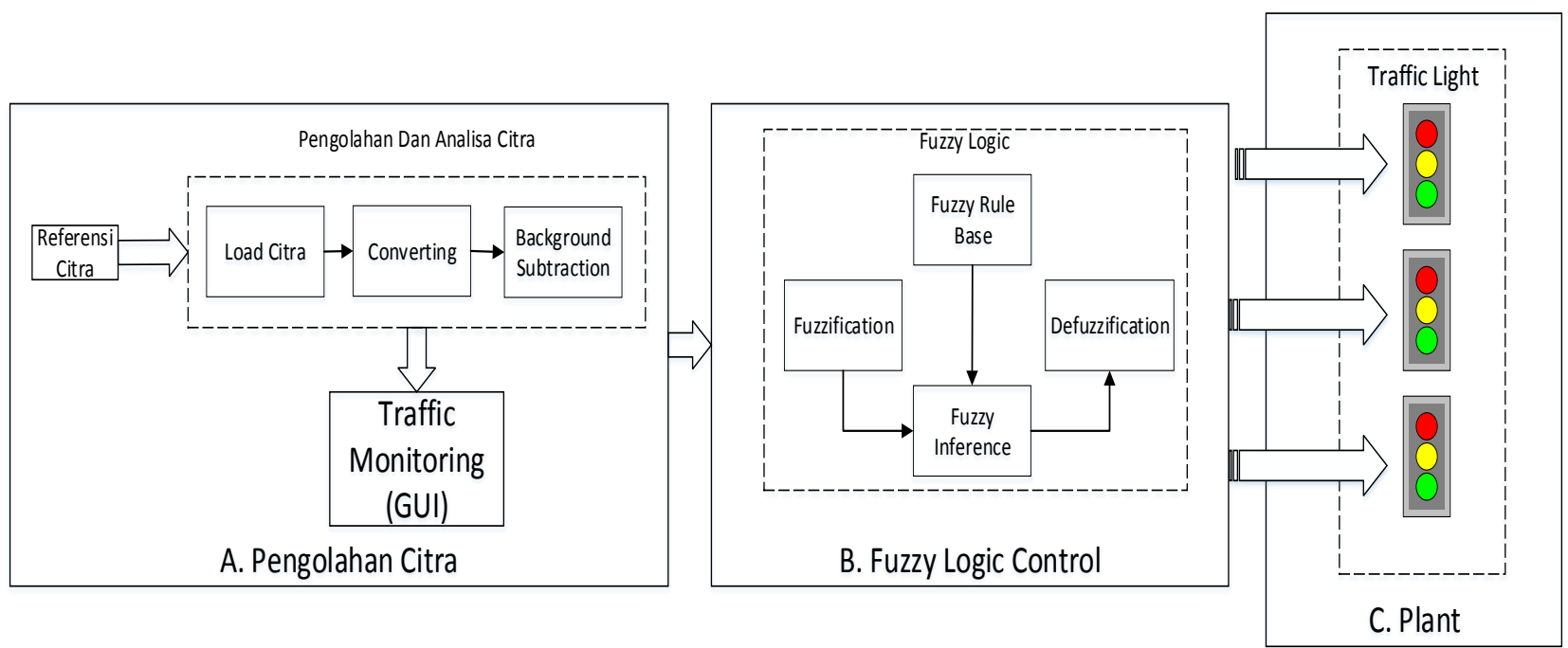

Gambar 3 Diagram blok skema traffic light adaptive

Prinsip dari background subtraction yaitu dengan cara mengurangkan antara citra masukan dengan citra referensi menggunakan metode pengurangan pada citra grayscale untuk memisahkan atau mempartisi antara citra background dan citra objek kemudian setelah proses segmentasi atau mempartisi objek, data tersebut kemudian diubah ke dalam citra biner, karena hanya mempunyai warna yaitu hitam atau putih.
Proses pengubahan citra biner agar memudakan untuk mengidentifikasi jumlah kendaraan dengan menghitung luasan area pixel objek dengan parameter yang ditentukan untuk kendaraan. Kemudian data proses pengindentifikasian kendaraan akan ditandai pada traffic monitoring dan penghitungan jumlah kendaraan akan ditampilkan di Graphical User Interface (GUI) visual traffic monitoring dan dijadikan masukan untuk kendali logika fuzzy. 
Kendali logika fuzzy yaitu bagian yang berfungsi untuk mengontrol lama nyala waktu hijau dari keluaran yang dihasilkan oleh pengolahan citra digital. Keluaran dari proses pengolahan citra dijadikan masukan fuzzy logic control (FLC) dengan beberapa tahapan dari proses fuzzifikasi, inferensi, dan defuzzifikasi untuk mendapatkan nilai crisp output untuk lama waktu hijau kemudian waktu tunggu jalur selanjutnya yaitu jumlah dari lama waktu hijau di kedua jalur traffic light.

Masukan kendali logika fuzzy sistem traffic light terdiri atas dua macam variabel yaitu jumlah kendaraan (JK) dalam satuan buah, waktu tunggu (WT) dalam satuan detik. Keluaran berupa durasi waktu hijau (WH) dalam satuan detik.

Masukan pertama, JK akan dibagi menjadi 4 fungsi keanggotaan yaitu sedikit (Sd), Sedang (Md), padat $(\mathrm{Pd})$, dan sangat padat (Sp) dengan rentang [0;9]. Masukan kedua, WT akan dibagi menjadi 4 fungsi keanggotaan yaitu Sebentar (Sb), Normal (Nm), Lama (Lm), dan Sangat Lama (SL) dengan rentang $[5 ; 50]$.

Sedangkan keluaran, WH akan dibagi menjadi 4 fungsi keanggotaan yaitu cepat (Cpt), normal (Nrm), Lama (Lma), sangat lama (SIm) dengan rentang [0;45]. Sistem fuzzy tersebut dapat dilihat seperti pada Gambar 4.

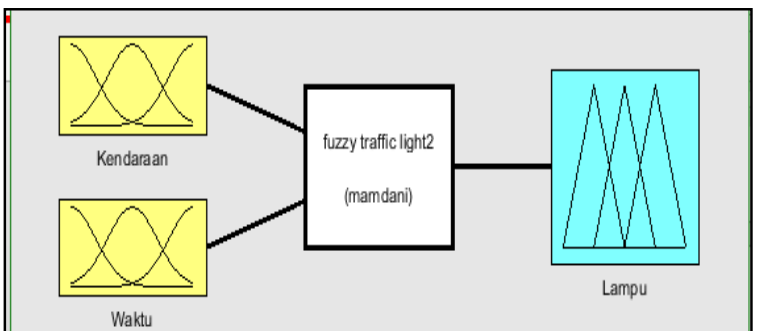

Gambar 4 .Sistem fuzzy dengan 2 Masukan

Sedangkan fungsi keanggotaan masing-masing masukan dan keluaran sistem fuzzy ditunjukkan seperti pada Gambar 5 s.d Gambar 7 berikut.

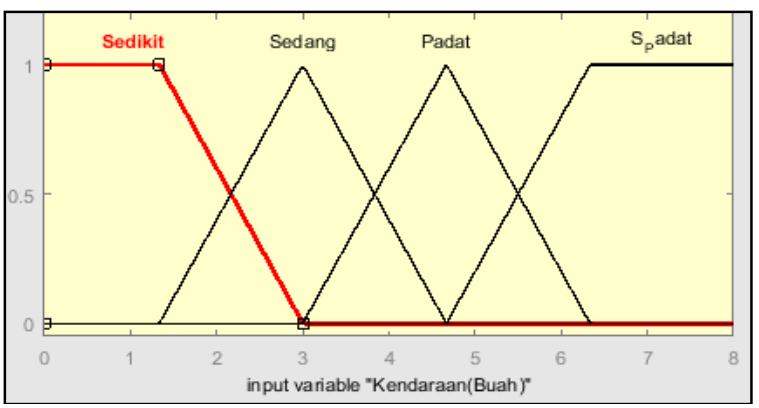

Gambar 5 Fungsi keanggotaan jumlah kendaraan (JK) a) Derajat keanggotaan sedikit JK

$\mu(x)= \begin{cases}1 ; & 0 \leq x \leq 1,33 \\ \frac{3-x}{3-1,33} ; & <1,33 x \leq 3\end{cases}$

b) Derajat keanggotaan sedang JK

$\mu(x)=\left\{\begin{array}{cc}0 ; & x \leq 1,33, x \geq 4,66 \\ \frac{x-1,33}{3-1,33} ; & 1<x \leq 3 \\ \frac{4,66-x}{4,66-3} ; & 3<x \leq 4,66\end{array}\right.$

c) Derajat keanggotaan Padat JK

$\mu(x)=\left\{\begin{array}{lc}0 ; & x \leq 3, x \geq 6,33 \\ \frac{x-3}{4,66-3} ; & 3<x \leq 4,66 \\ \frac{6,33-x}{6,33-4,66} ; & 4,66<x \leq 6,33\end{array}\right.$

d) Derajat keanggotaan sangat padat JK

$\mu(x)=\left\{\begin{array}{cl}\frac{x-4,66}{6,33-4,66} ; & 4,66<x<6,33 \\ 1 ; & 6,34 \leq x \leq 8\end{array}\right.$

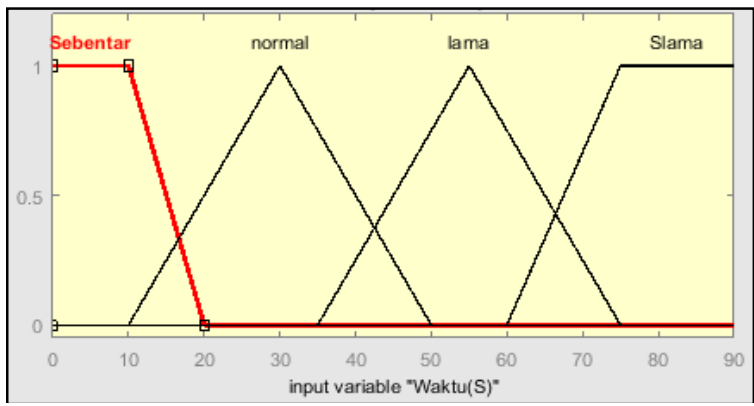

Gambar 6 Fungsi keanggotaan waktu tunggu (WT)

e) Derajat keanggotaan sebentar WT

$$
\mu(x)=\left\{\begin{aligned}
1 ; & 0 \leq x 10 \\
\frac{10-x}{20-10} ; & 10<x \leq 20
\end{aligned}\right.
$$

f) Derajat keanggotaan normal WT

$\mu(x)=\left\{\begin{array}{cr}0 ; & x \leq 10, x \geq 50 \\ \frac{x-10}{30-10} ; & 10<x \leq 30 \\ \frac{50-x}{50-30} ; & 30<x \leq 50\end{array}\right.$

g) Derajat keanggotaan lama WT

$\mu(x)=\left\{\begin{array}{lr}0 ; & x \leq 35, x \geq 75 \\ \frac{x-35}{55-35} ; & 35<x \leq 55 \\ \frac{75-x}{75-55} ; & 55<x \leq 75\end{array}\right.$ 
Seminar Nasional Instrumentasi, Kontrol dan Otomasi (SNIKO) 2018 Bandung, Indonesia, 10-11 Desember 2018

h) Derajat keanggotaan sangat lama WT

$\mu(x)= \begin{cases}\frac{x-60}{75-60} ; & 60<x<75 \\ 1 ; & 75 \leq x \leq 90\end{cases}$

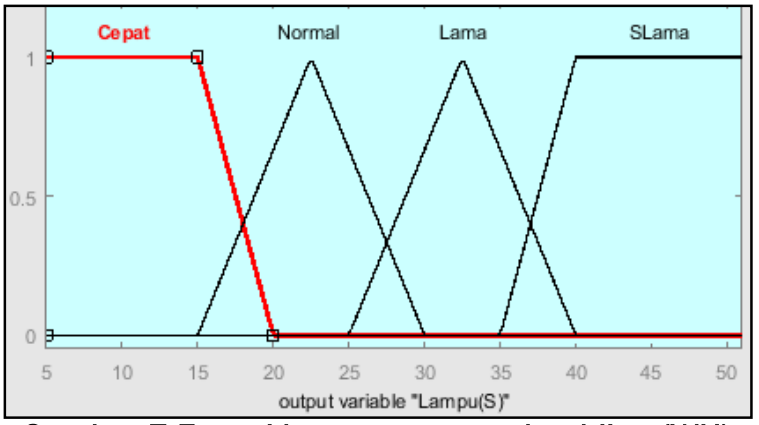

Gambar 7 Fungsi keanggotaan waktu hijau (WH)

i) Derajat keanggotaan cepat WH

$\mu(x)=\left\{\begin{aligned} 1 ; & & \leq x 15 \\ \frac{20-x}{20-15} ; & & 15<x \leq 20\end{aligned}\right.$

j) Derajat keanggotaan normal WH

$\mu(x)=\left\{\begin{array}{cc}0 ; & x \leq 10, x \geq 50 \\ \frac{x-15}{22,5-15} ; & 15<x \leq 22,5 \\ \frac{30-x}{30-22,5} ; & 22,5<x \leq 30\end{array}\right.$

k) Derajat keanggotaan lama WH

$$
\mu(x)=\left\{\begin{array}{cc}
0 ; & x \leq 25, x \geq 40 \\
\frac{x-25}{32,5-25} ; & 25<x \leq 32,5 \\
\frac{32,5-x}{40-32,5} ; & 32,5<x \leq 40
\end{array}\right.
$$

I) Derajat keanggotaan sangat lama WH

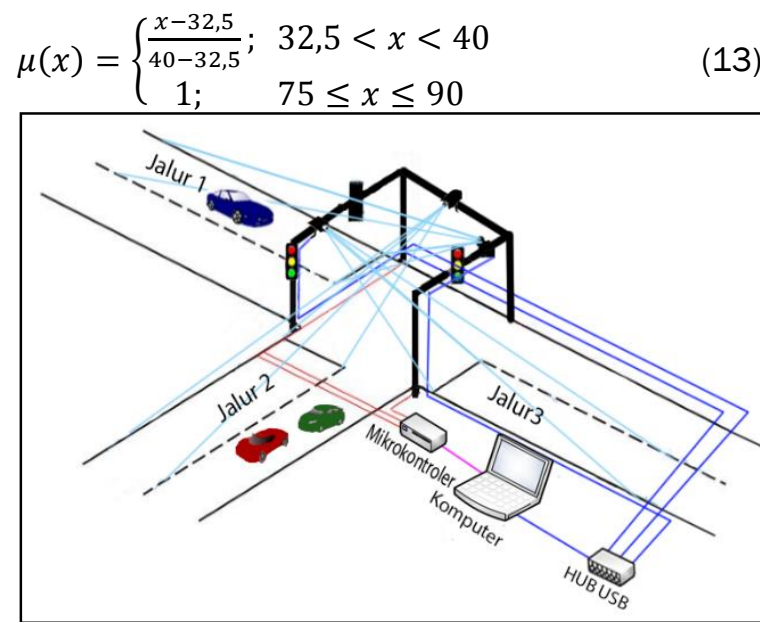

(a)
Tabel 2 Basis kaidah traffic light

\begin{tabular}{|c|c|c|c|c|}
\hline JK & $\mathrm{Sd}$ & $\mathrm{Md}$ & $\mathrm{Pd}$ & $\mathrm{SP}$ \\
\hline $\mathrm{Sb}$ & $\mathrm{Cpt}$ & $\mathrm{Cpt}$ & $\mathrm{Nrm}$ & $\mathrm{Nrm}$ \\
\hline $\mathrm{Nm}$ & $\mathrm{Cpt}$ & $\mathrm{Nrm}$ & $\mathrm{Nrm}$ & $\mathrm{Lma}$ \\
\hline $\mathrm{Lm}$ & $\mathrm{Nrm}$ & $\mathrm{Nrm}$ & $\mathrm{Lma}$ & $\mathrm{SIm}$ \\
\hline $\mathrm{SL}$ & $\mathrm{Lma}$ & $\mathrm{Lma}$ & $\mathrm{SIm}$ & $\mathrm{SIm}$ \\
\hline
\end{tabular}

Sistem fuzzy pada penelitian ini dibangun dengan 16 aturan. Adapun aturan-aturan tersebut ditunjukkan seperti pada Tabel 2

Plant yaitu pada traffic lights yaitu sebagai wadah atau peralatan, yang menginterpretasikan atau memvisualisasikan lama waktu hijau dan waktu tunggu dari keluaran proses FLC.

\subsection{Perancangan Miniatur Traffic light}

Perangkat keras pada Tugas Akhir berupa miniatur Traffic light persimpangan J. Baros yang di daerah Cimahi. Sebelum proses pembuatan miniatur telah dilakukan observasi untuk mengetahui desain dan ukuran tempat tersebut, selanjutnya dicari ukuran yang tepat untuk diterapkan dalam bentuk miniatur menggunakan skala perbandingan sehingga hasil program bisa mendekati hasil sesungguhnya apabila diterapkan secara real seperti pada Gambar 8.

Skla perbandingan yang digunakan adalah 1:100 yang didapatkan berdasarkan hasil perhitungan.

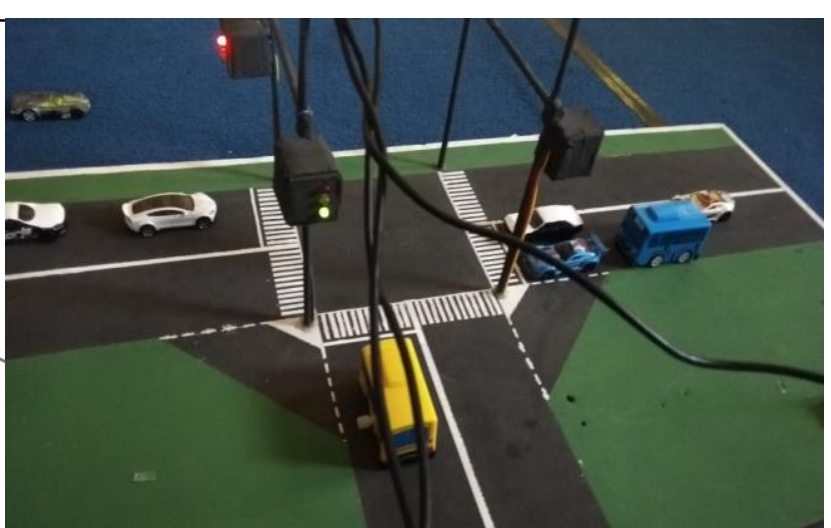

(b)

Gambar 8 Kit simulator; (a) ilustrasi, (b) rill 
Skala perbandingan 1:100, sehingga panjang miniatur yang ingin dibuat menjadi $90 \mathrm{~cm}$, dan lebar $48 \mathrm{~cm}$. Hasil dimensi miniatur tersebut diperoleh dari penghitungan sebagai berikut:

Diketahui: Skala 1:100

- lebar jalan sesungguhnya(LS)=15.5m : 2 $=7,75 \mathrm{~m} /$ jalur

- Panjang sesungguhnya(PS) $20 \mathrm{~m}=2000 \mathrm{~cm}$

- Ketinggian Kamera sesungguhnya $(\mathrm{KS})=15 \mathrm{~m}=$ $1500 \mathrm{~cm}$

Dicari: $\mathrm{Pm}, \mathrm{Tm}, \mathrm{Km}$

Penyelesaian:

- $\quad$ Panjang miniatur $(\mathrm{Pm})=2000 / 100$ $=20 \mathrm{~cm} /$ jalur $\quad 20 \times 2=40 \mathrm{~cm}$

- Lebar miniatur (Lm)=1550/100

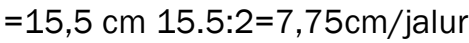

- Ketinggian kamera miniatur $(\mathrm{Km})$ $=1500 / 100=15 \mathrm{~cm}$

\subsection{Pengujian citra digital laboratorium kit}

Pengujian keseluruhan merupakan pengujian dengan menggabungkan seluruh bagian dari sistem yang berupa perangkat keras maupun perangkat lunak. Hasil gambar masukan dari sensor kamera akan diterima oleh PC yang selanjutnya dilakukan proses grayscale, backround subtraction, thresholding sehingga didapatkan kondisi kepadatan kendaraan, yaitu sepi, normal atau padat. Data kondisi kepadatan kendaraan akan dikirimkan ke mikrokontroler melalui port serial.

Mikrokontroler akan mengatur nyala lampu lalu lintas disetiap simpang. Arah pergerakan lampu lalu lintas adalah searah jarum jam. Berikut gambar tampilan program simulasi pengaturan lampu lalu lintas berbasis pengolahan citra digital pada Gambar 9 dan diberi nama perangkat lunak visual traffic monitoring.

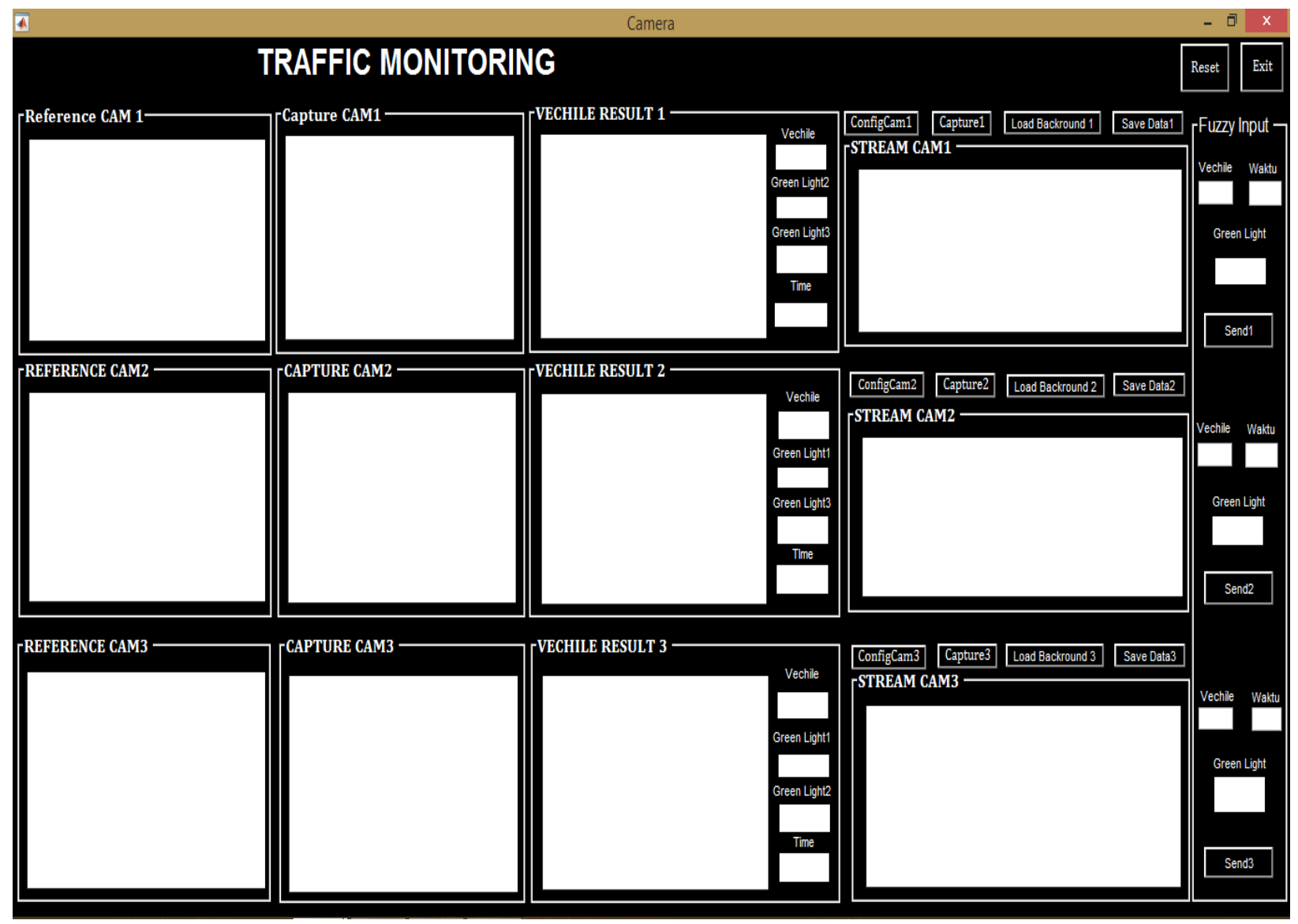

Gambar 10 perangkat lunak laboratorium kit

Pengujian pengambilan citra dilakukan dengan streaming kamera yang mengintegrasikan MATLAB 2015b melalui library Osgeneric webcam. Tujuannya untuk menampilkan data citra dari webcam ke aplikasi pada visual traffic monitoring dan dapat langsung diproses oleh program. Adapun konfigurasi visual traffic monitoring ditunjukkan pada Tebel 3. Integrasi tersebut merupakan langkah pengolahan citra digital dan hasilnya dapat langsung di tampilkan pada perangkat lunak. 
Tebel 3 Konfigurasi perangkat lunak laboratorium kit

\begin{tabular}{|l|l|}
\hline \multicolumn{1}{|c|}{ Nama Tombol } & \multicolumn{1}{c|}{ Fungsi } \\
\hline ConfigCam 1 s.d 3 & Memilih konfigurasi kamera yang akan digunakan \\
\hline Load 1 s.d 3 & Mengambil gambar referensi untuk proses background subtraction \\
\hline Capture 1 s.d 3 & Mengambil gambar masukan atau citra sampel untuk proses background subtraction \\
\hline Save data 1 s.d 3 & Untuk memulai menghitung jumlah kendaraan yang terdeteksi. \\
\hline Reset & Untuk mengubah data kembali menjadi 0 atau seperti awal kembali \\
\hline Exit & Keluar dari menu program citra digital \\
\hline Send 1 s.d 3 & Mengirimkan keluaran lampu hijau dari proses logika fuzzy ke Mikrokontroler \\
\hline
\end{tabular}

Pengujian Background Subraction dilakukan dengan membandingkan antara citra referensi dan citra sampel dengan cara menampilkan window image yang berisi hasil subtraksi dari area kondisi jalan. Tujuan pengujian yaitu untuk mengetahui aplikasi dapat melakukan subtraksi/pengurangan pixel citra referensi dengan citra sampel. Hasil dari pengujian adalah mengetahui program dapat mengurangkan antara pixel grayscale dari citra referensi dan dari citra sampel dengan pixel grayscale.

Berikut merupakan hasil proses background subtraction dari hasil pengujian di MATLAB di setiap jalur dengan kondisi yang berbeda-beda di tiap-tiap jalur persimpangan maket. Berdasarkan Tabel 4-5 dapat dilihat hasil proses background subtraction untuk tiap persimpangan. kelebihan dari proses background subtraction yaitu hasil segmentasi antara citra referensi dan citra sampel bagus atau terlihat jelas, namun kelemahan metode background subtraction yaitu apabila citra sampel yang tidak sesuai dengan citra referensi atau ada perbedaan posisi maka objek tersebut akan dianggap objek karena tidak tersubtraksi, maka harus dilakukan proses filtering untuk mengurangi kesalahan. Apabila citra sampel yang terdapat objek yang warnanya sesuai dengan background image, objek tersebut akan tersubtraksi sehingga bentuk objek ada sebagian hilang ataupun hilang semua karena proses dari background subtraction dan filtering-nya. Tahap akhir dari proses pengolahan citra adalah menghitung jumlah kendaraan serta menandai kendaraan tersebut dengan memebrikan kotak.

Tabel 4 Hasil proses pengolahan citra digital

\begin{tabular}{|l|l|l|l|l|}
\hline Jalan & Citra referensi & Citra sampel & $\begin{array}{c}\text { Background } \\
\text { subtraction }\end{array}$ & Thresholding \\
\hline 1 & & & &
\end{tabular}


Tabel 5 Hasil proses pengolahan citra digital

\begin{tabular}{|l|l|l|l|l|}
\hline Jalan & Citra referensi & Citra sampel & Filtering & Menghitung jumlah \\
kendaraan
\end{tabular}

\subsection{Pengujian algoritma logika fuzzy}

Pengujian dilakukan dengan membandingkan hasil program kendali logika fuzzy yang di unggah pada mikrokontroler ATmega16 dengan simulasi modul fuzzy menggunakan fuzzy logic Toolbox pada MATLAB. Pengujian dilakukan dengan berbagai nilai masukan untuk melihat nilai keluaran. Nilai jumlah kendaraan didapat dari kondisi jalan sesuai dengan capture traffic persimpangan jalan yang didapat dari visual traffic monitoring.
Pada pembuatan sistem terdapat dua masukan, masing-masing masukan mempunyai empat fungsi keanggotaan sehingga basis kaidah yang digunakan adalah sebanyak 16.

Dalam menganalisis logika fuzzy diambil 2 penghitungan yang pertama melihatkan hasil logika fuzzy menggunakan MATLAB dan penghitungan manual. Pada penghitungan manual diambil 9 sampel penghitungan keluaran fuzzy menggunakan rumus Mean of Maxima (MOM) pada Tabel 6.

Tabel 6 Perbandingan hasil algoritma logika fuzzy

\begin{tabular}{|c|c|c|c|c|c|c|c|}
\hline \multirow{2}{*}{ Siklus } & \multirow{2}{*}{\multicolumn{2}{|c|}{$\sum$ Kendaraan }} & \multirow{2}{*}{$\begin{array}{c}\sum \text { Hijau } \\
\text { Sebelumnya } \\
\text { (s) }\end{array}$} & \multicolumn{3}{|c|}{ Output } & \multirow{2}{*}{$\begin{array}{c}\text { Error } \\
(\%)\end{array}$} \\
\hline & & & & $\begin{array}{c}\text { Analisa } \\
\text { Fuzzy }\end{array}$ & FLT & $\begin{array}{c}\text { Lampu } \\
\text { Hijau (s) }\end{array}$ & \\
\hline \multirow{3}{*}{1} & fase 1 & 3 & 0 & 10 & 9,83 & 10 & 1,729 \\
\hline & fase 2 & 1 & 10 & 10 & 9,83 & 10 & 1,729 \\
\hline & fase 3 & 4 & 20 & 22,5 & 22,5 & 22 & 2,222 \\
\hline \multirow{3}{*}{2} & fase 4 & 5 & 32 & 22,5 & 22,5 & 22 & 2,222 \\
\hline & fase 5 & 2 & 44 & 22,6 & 22,7 & 23 & 1,321 \\
\hline & fase 6 & 3 & 45 & 22,49 & 22,5 & 22 & 2,222 \\
\hline \multirow{3}{*}{3} & fase 7 & 6 & 45 & 43,7 & 44,3 & 44 & 0,677 \\
\hline & fase 8 & 2 & 66 & 22,6 & 22,7 & 23 & 1,321 \\
\hline & fase 9 & 2 & 67 & 32,65 & 32,6 & 33 & 1,226 \\
\hline \multicolumn{2}{|c|}{ Rata Rata } & 2,8 & 32,9 & 23,23 & 23,27 & 23,22 & 1,467 \\
\hline
\end{tabular}


Berdasarkan hasil pengujian keluaran lama lampu hijau pada Tabel 2 yaitu kondisi untuk mempertahankan lama lampu hijau fase yang sedang aktif sesuai dengan data masukan jumlah kendaraan, semakin banyak data jumlah kendaraan pada proses kendali logika fuzzy maka keluaran lampu hijau yang dikeluarkan semakin lama.

\section{Kesimpulan}

Kit laboratorium untuk mata kuliah pengolahan citra digital dan mata kuliah instrumentasi cerdas dapat dibangun dengan skenario menghitung jumlah kendaraan pada suatu simpang dan agar dapat mendapatkan kesempatan lama lampu hijau tertentu dapat dikombinasikan dengan algoritma kecerdasan berupa logika fuzzy untuk menentukan dan memutuskan lama lampu hijau menyela.

Konsep lalu lintas adaptif untuk laboratorium kit dapat dibangun menggunakan GUI sebagai perangkat lunak yang digunakan untuk melakukan proses pendeteksian jumlah kendaraan menggunakan yang erdeteksi kamera pada setiap simpang jalan. komponen lain yaitu mikrokontroler yang dapat ditanam algoritma kecerdasan buatan sehingga dapat memberikan keputusan berdasarkan masukan yang diberikan.

Berdasarkan hasil pengujian ada perancangan kecerdasan menggunakan logika fuzzy pada tiaptiap percobaan memiliki output yang dapat menyesuaikan dengan kondisi masukan yang diberikan. Dari percobaan 3 siklus tersebut menunjukan bahwa kendali logika fuzzy dapat mengatur waktu lampu hijau sesuai dengan masukan jumlah kendaraan pada setiap simpang, kondisi tersebut sudah dihitung secara manual dan diverifikasi menggunakan simulasi fuzzy logic toolbox pada MATLAB dengan presentase error $1,467 \%$

Berdasarkan hasil simulasi lampu lalu lintas adaptif menggunakan pengolahan citra dan instrumentasi cerdas yaitu dapat menggambarkan performansi dari penyalaan waktu lampu hijau pada lampu lalu lintas, sehingga waktu tunggu kendaraan yang hendak melintasi persimpangan dapat diminimasi.

\section{Daftar Pustaka}

[1] A. G. Abdullah, D. L. Hakim, M. A. Auliya, and A. B. Dani, "Low-cost and Portable Process
Control Laboratory Kit," TELKOMNIKA (Telecommunication Comput. Electron. Control., vol. 16, no. 1, pp. 232-240, 2018.

[2] I. Kukliansky and H. Eshach, "Evaluating a Contextual-Based Course on Data Analysis for the Physics Laboratory," J. Sci. Educ. Technol., vol. 23, no. 1, pp. 108-115, 2014.

[3] B. H. Sababha, "Project-Based Learning to Enhance Teaching Embedded Systems," EURASIA J. Math. Sci. Technol. Educ., vol. 12, no. 10, pp. 2575-2585, 2016.

[4] M. Petkovski and M. Kostov, "Model Based Design and Hardware in the Loop Testing in Power Electronics Courses," TEM J., vol. 1, no. 4, pp. 292-296, 2012.

[5] I. Indrianto, M. N. I. Susanti, R. Arianto, and R. Ruli, "Embedded System Practicum Module Design to Increase Student Comprehension of Microcontroller," TELKOMNIKA (Telecommunication Comput. Electron. Control., vol. 16, no. 1, pp. 53-60, 2018.

[6] E. Nugraha, A. G. Abdullah, and D. L. Hakim, "Designing a SCADA system simulator for fast breeder reactor," IOP Conf. Ser. Mater. Sci. Eng., vol. 128, no. 1, 2016.

[7] B. A. Khan and N. S. Lai, "An intelligent traffic controller based on fuzzy logic," in SDIWC, 2013, pp. 89-93.

[8] Toar-lumimuut, R. E. P. Tolah, R. Sengkey, and Y. D. Y. Rindengan, "Perancangan Simulasi Otomatis Traffic light Menggunakan Citra Digital Studi Kasus," E-journal Tek. Elektro dan Komput., vol. 4, no. 4, pp. 35-45, 2015.

[9] Z. Jamal, M. Rusydi, F. I. Komputer, J. Z. A. Pagar, A. No, B. L. Indonesia, and T. Fax, "Development of Fuzzy Logic Controller For Trainer Kit Based on Microcontroller," no. 93, pp. 36-41, 2016.

[10] D. Handaya, D. Handaya, Y. Prima, and I. Auditia, "Simulasi Mesin Cuci Industri Tekstil Berbasis Kendali Fuzzy dan Interface LabVIEW 2014 Simulasi Mesin Cuci Industri Tekstil Berbasis Kendali Fuzzy dan Interface LabVIEW 2014," in Prosiding Simposium Nasional Inovasi dan Pembelajaran Sains 2016 (SNIPS 2016), 2016, July.

[11] D. I. Saputra, A. S. Muharrom, I. Taufiqurrahman, R. Fauziah, and A. Junaidi, "Simulasi Kendali Logika Fuzzy Di Ruang Merokok Menggunakan Mikrokontroler," in Seminar Nasional Microwave, Antena dan Propagasi (SMAP 2017), 2017, no. 1, pp. 8082. 